\title{
Erratum
}

The publisher regrets the incomplete address of the editors of this book.

\section{APOPTOSIS IN CARDIAC BIOLOGY}

Edited by:

Heribert Schunkert

G.A.J. Riegger

University of Regensburg

Germany

Kluwer Academic Publishers

Boston-Dordrecht-London 


\section{APOPTOSIS IN CARDIAC BIOLOGY}

Edited by:

Heribert Schunkert

G.A.J. Riegger

Klinik und Poliklinik fur Innere

Germany

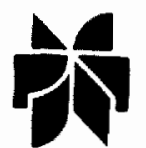

Kluwer Academic Publishers

Boston-Doredrecht-London 
Distributors for North, Central and South America:

Kluwer Academic Publishers

101 Philip Drive

Assinippi Park

Norwell, Massachusetts 02061 USA

Telephone (781) $871-6600$

Fax (781) 681-9045

E-Mail <kluwer@wkap.com>

Distributors for all other countries:

Kluwer Academic Publishers Group

Distribution Centre

Post Office Box 322

3300 AH Dordrecht, THE NETHERLANDS

Telephone 31786392392

Fax 31786546474

E-Mail <services@wkap.nl>

Electronic Services <http://www.wkap.nl>

\section{Library of Congress Cataloging-in-Publication Data}

A C.I.P. Catalogue record for this book is available from the Library of Congress.

Copyright ${ }^{\odot} 2000$ by Kluwer Academic Publishers

All rights reserved. No part of this publication may be reproduced, stored in a retrieval system or transmitted in any form or by any means, mechanical, photocopying, recording, or otherwise, without the prior written permission of the publisher, Kluwer Academic Publishers, 101 Philip Drive, Assinippi Park, Norwell, Massachusetts 02061

Printed on acid-free paper.

Printed in the United States of America 


\section{Contents}

List of Contributors .................................................................. vii

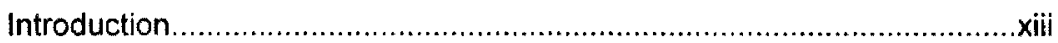

PART ONE: BASIC MECHANISMS OF APOPTOSIS

I.1 The initiation of apoptosis

I.1.1 Death receptors and their ligands .............................................. 5 Jürgen Holtz, Dorothea Darmer

Herbert Schwarz

1.1.3 Reactive oxygen species and apoptosis Rüdiger von Harsdorf

1.2 The mediators of apoptosis

1.2.1 Oncogenes and p53 ...

Franz Kohlhuber, Dirk Eick

1.2.2 BCL-2 family members and mitochondria.

KJaus Schlottmann, Jürgen Schölmerich

1.2.3 Inhibition of cardiac myocyte apoptosis by gp130-dependent cylokines ...91 Kai C. Wollert

1.2.4 Cell cycle regulation and apoptotic cell death.

Lothar Jahn, Harald Bär

1.3 The execution of apoptosis

1.3.1 Caspase cascades and caspase targets Thomas Rudel

1.3.2 Apoptosis: a distinctive form of cell death

L.B. Jordan, D.J. Harrison

\section{PART TWO: CELLULAR TARGETS IN THE CARDIOVASCULAR SYSTEM}

II. 1 Blood vessels

II.1.1 Apoptosis and cell cycle in endothelial cells 141 loakim Spyridopoulos 


\section{APOPTOSIS IN CARDIAC BIOLOGY}

\section{II.2 Myocardium}

II.2.1 Endurance under stress and cardioprotective functions by cardiac fibroblasts

Mahboubeh Eghbali-Webb

II.2.2 Cardiac myocytes

Armin Haunstetter, Markus Haass, Seigo Izumo

11.2.3 Cardiac myocytes and fibroblasts exhibit differential sensitivity to apoptosis-inducing stimuli

Edward G. Lakatta, Xilin Long, Alan Chesley, Michael Crow

\section{PART THREE: APOPTOSIS IN CARDIAC DISORDERS}

\section{III.1 Vascular disease}

III.1.1 Hypertension as a cardiovascular proliverative disorder

Denis deBlois, Sergei Orlov, Pavel Hamet

III.1.2 Apoptosis in human atherosclerosis

Gerhard Bauriedel, Randolph Hutter, Uirich Welsch, Berndt Lüderitz

III.2 Cardiac disease

III.2.1 Apoptosis in myocardial infarction

Andreas V. Sigel, Günter A.J. Riegger

111.2.2 Pro-inflammatory and pro-apoptotic factors in heart failure

Laura Agnoletti, Laura Comini, Guiseppina Gaia, Salvatore Curello,

Roberto Ferrari

III.2.3 Molecular mechanisms of cardiac myocardial remodeling during aging. Role of apoptosis

Ziad Mallat, Bernard Swynghedauw

III.2.4 Apoptosis during cardiac surgery

Hermann Aebert, Joachim P. Schmitt, Heribert Schunkert

\section{PART FOUR: THERAPEUTICAL OPTIONS}

IV.1 New opportunities for heart disease therapeutics .299

Giora Z. Feverstein

IV.2 Beta blocker therapy and prevention of apoptosis Andreas V. Sigel, Heribert Schunkert

IV.3 Apoptosis in cardiac myocytes - Role of the renin-angiotensin-system ...317 Daniela Grimm, Gilbert Schönfelder, Martin Paul

IV.4 Estrogens and the prevention of cardiac apoptosis Christian Grohé, Rainer Meyer, Hans Vetter

IV.5 Open questions on apoptosis in cardiac biology .337 Heribert Schunkert

Index 


\section{List of Contributors}

Privatdozent Dr. med. Hermann Aebert

Klinik und Poliklinik für Herz-, Thoraxund herznahe Gefäßchirurgie

University of Regensburg

Franz-Josef-Strauß-Allee 11

D-93053 Regensburg

Germany

Laura Agnoletti, M.D.

Cardiovascular Research Center

"Salvatore Maugeri" Foundation

Via Pinidolo, 23

I-25064 Gussago (Brescia)

Italy

\section{Dr. med. Harald Bär}

Department of Internal Medicine

University of Heidelberg

Bergheimer Straße 58

D-69115 Heidelberg

Germany

Prof. Dr. med. Gerhard Bauriedel,

FACC, FESC

Associate Professor, Department of Internal

Medicine II/Cardiology

University of Bonn

Sigmund-Freud-Straße 25

D-53105 Bonn

Germany

\section{Alan Chesley, Ph.D.}

Laboratory of Cardiovascular Sciences

Gerontology Research Center

National Institute on Aging, National Institutes

of Health

5600 Nathan Shock Drive

Baltimore, MD 21224

USA
Laura Comini, M.D.

Cardiovascular Research Center

"Salvatore Maugeri" Foundation

Via Pinidolo, 23

|-25064 Gussago (Brescia)

Italy

Michael T. Crow, Ph.D.

Laboratory of Cardiovascular Sciences

Gerontology Research Center

National Institute on Aging, National Institutes

of Health

5600 Nathan Shock Drive

Baltimore, MD 21224

USA

Salvatore Curello, M.D.

Chair of Cardiology

Spedali Civili

P.le Spedali Civili

1-25123 Brescia

Italy

Dr. rer. nat. Dorothea Darmer

Martin-Luther Universität Halle-Wittenberg

Institut für Pathophysiologie

Magdeburger Straße 18

D-06097 Halle

Germany

Denis deBlois, Ph.D.

CHUM Research Center

3840 St-Urbain

Montreal, Quebec

H2W IT8

Canada 
Mahboubeh Eghbali-Webb, Ph.D.

Department of Anesthesiology

Yale School of Medicine

333 Cedar Street

New Haven, CT 065/0

USA

Dr. rer. nat. Dirk Eick

Institut für Klinische Molekularbiologie und Tumorgenetik

GSF-Forschungszentrum für Umwelt und

Gesundheit

Marchioninistraße 25

D-81377 München

Germany

Roberto Ferrari, M.D.

Chair of Cardiology

University of Ferrara

"Salvatore Maugeri" Foundation

Via Pinidolo, 23

|-25064 Gussago (Brescia)

Italy

Giora Z. Feuerstein, M.D.

Senior Director, Cardiovascular Sciences

DuPont Pharmaceuticals Corporation

E400/3255

Route 141 \& Henry Clay Road

Wilmington, DE 19880-0400

USA

Guiseppina Gaia, M.D.

Cardiovascular Research Center

"Salvatore Maugeri" Foundation

Via Pinidolo, 23

I-25064 Gussago (Brescia)

Italy

Dr. med. Daniela Grimm

Institute of Clinical Pharmacology and

Toxicology

Benjamin Franklin Medical Center

FU-Berlin

Garystraße 5

D-14195 Berlin

Germany
Privatdozent Dr. med. Christian Grohé

Rheinische Friedrich-Wilhelms-Universität

Medizinische Univ..Poliklinik

Wilhelmstraße 35-37

D-53111 Bonn

Germany

Dr. med. Markus Haass

Department of Cardiology

University of Heidelberg

Bergheimer Straße 58

D-69115 Heidelberg

Germany

Pavel Hamet, M.D., Ph.D.

Professor of Internal Medicine

CHUM Research Center

3840 St-Urbain

Montreal, Quebec

H2W IT8

Canada

David J. Harrison, M.D.

Professor of Pathology

Department of Pathology

The University of Edinburgh

Medical School

Teviot Place

Edinburgh EH8 9AG.

United Kingdom

Dr. med. Rüdiger von Harsdorf

Franz-Volhard-Klinik

Humboldt-Universität

Universitätsklinikum Charité

Wiltbergstraße 50

D-13125 Berlin

Germany

Dr. med. Armin Haunstetter

Department of Cardiology

University of Heidelberg

Bergheimer Straße 58

D.69115 Heidelberg

Germany 
Prof. Dr. med. Jürgen Holtz

Professor of Physiology

Martin-Luther Universität Halle-Wittenberg

Institut für Pathophysiologie

Magdeburger Straße 18

D-06097 Halle

Germany

Dr. med. Randolph Hutter

Department of Internal Medicine II/Cardiology

University of Bonn

Sigmund-Freud-Straße 25

D.53105 Bonn

Germany

Seigo Izumo, M.D.

Cardiovascular Division

Beth Israel Deaconess Medical Center

Harvard Medical School

330 Brookline Ave.

Boston, MA 02215

USA

Privatdozent Dr. med. Lothar Jahn

Department of Internal Medicine

University of Heidelberg

Bergheimer Straße 58

D-69115 Heidelberg

Germany

Lee Baines Jordan, B.Sc.(Hons),

M.B., Ch.B.

Department of Pathology

The University of Edinburgh

Medical School

Teviot Place

Edinburgh EH8 9AG.

United Kingdom

Dr. rer. nat. Franz Kohlhuber

Institut für Klinische Molekularbiologie

und Tumorgenetik

GSF-Forschungszentrum für Umwelt und

Gesundheit

Marchioninistraße 25

D-81377 München

Germany
Edward G. Lakatta, M.D., Ph.D.

Laboratory of Cardiovascular Sciences

Gerontology Research Center

National Institute on Aging, National Institutes

of Health

5600 Nathan Shock Drive

Baltimore, MD 21224

USA

Xilin Long, M.D.

Laboratory of Cardiovascular Sciences

Gerontology Research Center

National Institute on Aging, National Institutes of Health

5600 Nathan Shock Drive

Baltimore, MD 21224

USA

Prof. Dr. med. Berndt Lüderitz,

\section{FACC, FESC}

Professor of Internal Medicine

Department of Internal Medicine I/Cardiology

University of Bonn

Sigmund-Freud-Sraße 25

D-53105 Bonn

Germany

Ziad Mallat, M.D.

U141-INSERM-Hospital Lariboisière

$41 \mathrm{Bd}$ de la Chapelle

F-75475 Paris Cedex

France

Privatdozent Dr. rer. nat. Rainer Meyer Rheinische Friedrich-Withelms-Universität Physiologisches Institut Wilhelmstraße 31

D-53111 Bonn

Germany

Sergei Orlov, Ph.D.

CHUM Research Center

3840 St-Urbain

Montreal, Quebec

H2W IT8

Canada 
Prof. Dr. med. Martin Paul

Professor of Pharmacology and Toxicology Institute of Clinical Pharmacology and

Toxicology

Benjamin Franklin Medical Center

FU-Berlin

Garystraße 5

D-14195 Berlin

Germany

Prof. Dr. med. Günter A.J. Riegger

Professor of Internal Medicine

University of Regensburg

Franz-Josef-Strauß-Allee 11

D-93053 Regensburg

Germany

Dr. rer. nat. Thomas Rudel

Max-Planck-Institute for Infection Biology

Department of Molecular Biology

Monbijoustraße 2

D-10117 Berlin

Germany

Dr. med. Klaus Schlottmann

Department of Internal Medicine

University of Regensburg

Franz-Josef-Strauß-Allee 11

D-93053 Regensburg

Germany

Dr. med. Joachim P. Schmitt

Klinik und Poliklinik für Herz-, Thorax-

und herznahe Gefäßchirurgie

University of Regensburg

Franz-Josef-Strauß-Allee 11

D-93053 Regensburg

Germany

Prof. Dr. med. Jürgen Schölmerich

Professor of Internal Medicine

University of Regensburg

Franz-Josef-Strauß-Allee 11

D-93053 Regensburg

Germany
Dr. med. Gilbert Schönfelder

Institute of Clinical Pharmacology and

Toxicology

Benjamin Franklin Medical Center

FU-Berlin

Garystraße 5

D-14195 Berlin

Germany

Prof. Dr. med. Heribert Schunkert

Professor of Clinical and Molecular Cardiology

University of Regensburg

Franz-Josef-Strauß-Allee 11

D-93053 Regensburg

Germany

Dr. rer. nat. Herbert Schwarz

Department of Pathology

University of Regensburg

Franz-Josef-Strauß-Allee 11

D-93053 Regensburg

Germany

Dr. med. Andreas V. Sigel

Department of Internal Medicine

University of Regensburg

Franz-Josef-Strauß-Allee 11

D-93053 Regensburg

Germany

loakim Spyridopoulos, M.D.

Department of Cardiology and Cardiovascular

Research

Medizinische Klinik Tübingen

Otfried-Müller-Straße 10

D-72076 Tübingen

Germany

Bernard Swynghedauw, M.D.

Professor of Physiology

U127-INSERM-Hospital Lariboisière

$41 \mathrm{Bd}$ de la Chapelle

F-75475 Paris Cedex

France 
Prof. Dr, med. Hans Vetter

Rheinische Friedrich-Wilheims-Universität

Medizinische Univ.-Poliklinik

Wilhelmstraße 35-37

D.53111 Bonn

Germany

Dr. med. Ulrich Welsch

Department of Anatomy III

University of Munich

Pettenkoferstraße 11

D-80336 München

Germany

Dr. med. Kai C. Wollert

Department of Cardiology and Angiology

Medizinische Hochschule Hannover

Carl-Neuberg-Straße 1

D-30625 Hannover

Germany 


\section{Introduction}

Cardiac myocytes are, for the most part, terminally differentiated and non-renewing cells. Thus, the functional and structural integrity of cardiac myocytes needs to be maintained during the entire lifespan. In this context, it appears almost contraintuitively that cardiac myocytes accommodate a complex machinery for self destruction. Obviously, this machinery has to be kept under tight control such that coordinated self elimination does not occur accidentally. Rather, apoptosis must be reserved for rather desperate conditions in which necrosis with inflammatory responses may be the only alternative fate for a malfunctioning cell.

The question arises if excessive or unintentional activation of apoptosis is involved in the precipitation or progression of cardiovascular diseases, i.e. the leading causes for morbidity and mortality in industrialized countries. Moreover, what are the factors that push cardiac cells involuntarily into death and what are the precise mechanisms that are activated along this path. Comprehensive answers to these questions are certainly a major challenge for nowadays cardiovascular research.

Deepening our knowledge on apoptosis in cardiac biology emerges to be a timely goal in this context, both for clinical practice as well as basic research in cardiology. In particular, the appropriate integration of the functional consequences related to apoptosis appear to be essential for a complete understanding of the pathophysiology of cardiac diseases. Likewise, the potential benefits achieved by the abrogation of apoptosis need to be defined by future research. Subsequently, new treatment modalities focused on apoptotic cell death will require careful evaluation in experimental models and ultimately in patients with heart failure or myocardial infarction.

Fortunately, the forefront of apoptosis research is in a phase of rapid expansion and creative molecular biological techniques are being increasingly introduced for the exploration of cardiac cell death. This book reflects these advances and starts with a series of chapters on basic mechanisms of apoptosis. The complex system required to keep apoptosis in custody, for the most part, as well as the components of the death machinery itself will be distinctly presented. Next, the cellular targets of apoptosis in the heart and the cardiovascular system will be lined up and discussed with respect to their susceptibility to programmed cell death. The current conception of the role of apoptosis in the course of myocardial infarction, heart failure, and hypertension is next being presented. Finally, pharmacological interventions that are directed to the genuine mechanisms as well as the initiating factors of programmed cell death are being described. 
Thus, Apoptosis in Cardiac Biology, written by a team of internationally renowned researchers, gives a timely synopsis of programmed cell death in the heart. We hope that the book will provide candid guidance into the emerging fields of apoptosis for the cardiologist with interest in basic mechanisms of heart disease as well as the basic scientist with interest in a comprehensive overview on the subject.

Our appreciation goes to Professor Bernard Swynghedauw who encouraged us and our fellow contributors to edit this volume. The Working Group on Heart Failure of the European Society of Cardiology as well as the Arbeitsgruppe fur Molekularbiologie und Gentechnologie of the German Society of Cardiology provided further in valuable support. Finally, our special thanks go to Frau Irene Brandl, University of Regensburg, and Ms Elaine Bello, Kluwer Academic Publishers, who have to be acknowledged for their outstanding expertise and patience during the realization of this book.

Regensburg

H. Schunkert and G. Riegger 
APOPTOSIS IN CARDIAC BIOLOGY 


\section{BASIC SCIENCE FOR THE CARDIOLOGIST}

1. B. Levy, A. Tedgui (eds.): Biology of the Arterial Wall. 1999

ISBN 0-7923-8458-X

2. M.R. Sanders, J.B. Kostis (eds): Molecular Cardiology in Clinical

Practice. 1999. ISBN 0-7923-8602-7

3. B. Swynghedauw (ed.): Molecular Cardiology for the Cardiologist. Second Edition. 1998.

ISBN: 0-7923-8323-0

4. B. Ostadal, F. Kolar (eds.): Cardiac Ischemia: From Injury to Protection. 1999.

ISBN: 0-7923-8642-6

5. H. Schunkert, G.A.J. Riegger (eds.): Apoptosis in Cardiac Biology

ISBN: 0-7923-8648-5

KLUWER ACADEMIC PUBLISHERS - DORDRECHT/BOSTON/LONDON 